\title{
Design and Testing of a 10KW Steam Turbine for Steam Turbochargers
}

M. Rautenberg, M. Malobabic

Institute for Turbomachinery, University of Hannover, West Germany

\author{
A. Mobarak \\ Faculty of Engineering, Cairo University, Egypt
}

and

\author{
M. Abdel Kader \\ Faculty of Engineering, Suez Canal University, Egypt
}

\begin{abstract}
A Clausius-Rankine-cycle has been proposed to recover waste heat from a piston engine. This waste heat is then used to supercharge the cylinders by means of a steam turbocharger. The advantage of using this steam turbocharger system is to avoid the losses due to the engine back pressure which accompany the use of the conventional exhaust gas turbocharger. The mass flow rate of turbines for steam turbochargers in the range from 1 to $10 \mathrm{kw}$ is about 0.03 to $0.08 \mathrm{~kg} / \mathrm{s}$. This implies a special turbine design, characterised by partial admission and supersonic flow, which unfortunately leads to low turbine efficiencies. A small Pelton turbine for steam has been designed and produced. The turbine is connected to the radial compressor of a conventional exhaust gas turbocharger which works, in this case, as a brake to dissipate the generated turbine power. A special test rig has been built to carry out the experimental investigations on the proposed Pelton turbine. The test rig is supplied with superheated steam from the University's power plant. Two different rotors for this Pelton turbine have been tested under the same operating conditions (rotor 2, see Fig. 1). Some experimental test results of a special Pelton turbine are presented and discussed in this report.
\end{abstract}

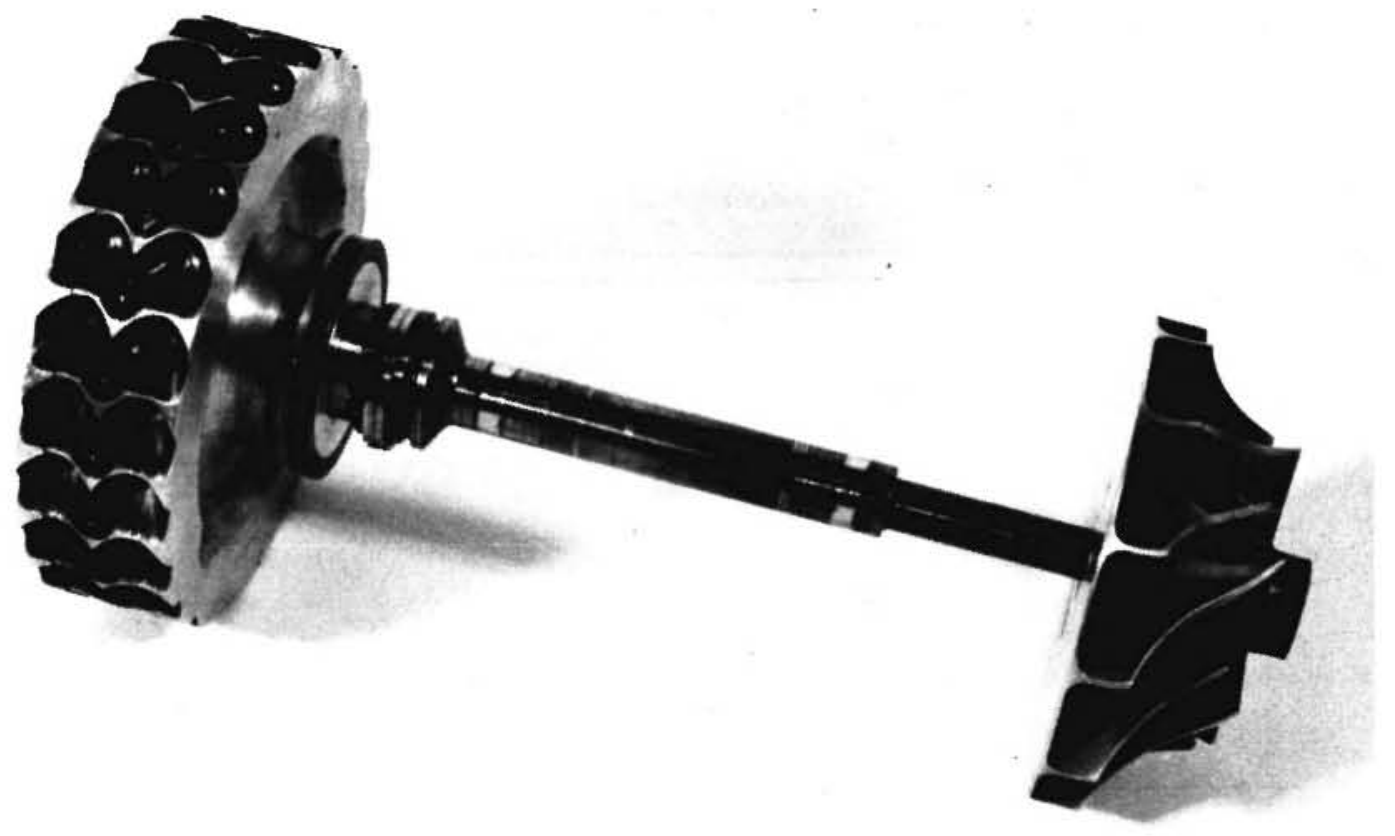

Fig. 1: View of a tested Pelton turine rotor (a) and compressor rotor (b). 


\section{Nomenaclature}

$\begin{array}{ll}\mathrm{c} & \text { flow velocity }(\mathrm{m} / \mathrm{s}) \\ \mathrm{d} & \text { rotor diameter }(\mathrm{m}) \\ \mathrm{h} & \text { enthalpy }(3 / \mathrm{kgK})) \\ \mathrm{m} & \text { mass flow }(\mathrm{kg} / \mathrm{s}) \\ \mathrm{n} & \text { rotational speed }(\mathrm{rpm}) \\ \mathrm{p} & \text { pressure }(\mathrm{Pa}) \\ \mathrm{t} & \text { torque }(\mathrm{Nm}) \\ \mathrm{u} & \text { circumferential speed }(\mathrm{m} / \mathrm{s}) \\ \mathrm{W} & \text { relative flow velocity }(\mathrm{m} / \mathrm{s}) \\ \mathrm{M} & \text { Mach number } \\ \mathrm{P} & \text { power }(\mathrm{kW}) \\ \mathrm{T} & \text { temperature }(\mathrm{K}) \\ \mathrm{V} & \text { volume }\left(\mathrm{m}^{3}\right) \\ \beta & \text { relative flow angle }\left({ }^{\circ}\right) \\ \eta & \text { efficiency } \\ \nu & \text { velocity ratio } \mathrm{u}_{\mathbf{3 . 1}} / \mathrm{c}_{\mathbf{3}, 1 . \mathrm{s}} \\ \pi & \text { pressure ratio } \\ \Delta & \text { difference }\end{array}$

\section{Subscripts}

$\begin{array}{ll}\text { a } & \text { air } \\ \text { ad } & \text { adiabetic } \\ \text { c } & \text { compressor } \\ \text { cor } & \text { corrected }(1.013 \text { bar; } 288 \mathrm{~K}) \\ \text { e } & \text { engine } \\ \text { i } & \text { inner } \\ \mathrm{m} & \text { middle } \\ \text { max } & \text { maximum } \\ \mathrm{n} & \text { nozzle } \\ \mathrm{o} & \text { outer } \\ \mathrm{s} & \text { isentropic } \\ \text { st } & \text { steam } \\ \text { sw } & \text { swept } \\ \mathrm{t} & \text { turbine } \\ \text { tot } & \text { total } \\ 1 & \text { compressor inlet } \\ 2 & \text { compressor exit } \\ 3 & \text { turbine inlet } \\ 4 & \text { turbine exit } \\ 3,1 & \text { turbine rotor inlet } \\ 4,2 & \text { turbine rotor exit }\end{array}$

\section{Introduction}

The turbines of the exhaust gas turbocharger systems currently being used are either constant pressure arrangements or pulse type turbochargers. Both get their power by banking-up the exhaust gas flow and from the kinetic energy of the exhaust gases, and to a much lesser extent from the thermal energy of the exhaust gases. In order to achieve sufficient engine response from the supercharged combustion engines, today's turbochargers are designed for an exhaust mass flow rate which is less than the design mass flow rate of the engine, thereby enabling the achievement of higher turbine speeds, even when the number of engine revs is low. This guarantees an improved response by the charger in the low engine speed range. However, in the high engine speed and load range this would lead to extremely high values of turbine inlet pressure, turbocharger speed and boost pressure. So, making use of a waste gate with this type of turbocharger is absolutely necessary. This means that with high loads, and in the upper speed range, up to 50\% and more of the exhaust mass flow must be throttled in the waste gate in order to avoid exceeding the maximum turbocharger speed and boost pressure. Despite the use of a waste gate, the conventional turbocharger has one main shortcoming: a considerable increase in engine backpressure $p_{3}$ (turbine inlet pressure) in the upper engine speed and load range. Since the boost pressure should be kept constant over a wide scale of engine speeds, the compressor with increasing engine speed and load requires more power because of the rise in air consumption of the engine. So, in the case of a waste gate controlled turbocharger, where the whole exhaust mass flow is not carried through the turbine, the necessary mechanical power to drive the compressor is covered by a higher turbine inlet pressure $p_{3}$ as is the case when using a larger turbine, designed for the maximum engine exhaust mass flow, where the same power is generated by a greater mass flow but at a lower level of $p_{3}$. As a result, the displacement work of the engine is increased and this leads to a reduction of the engine efficiency associated with an increase in the specific fuel consumption.

These above mentioned disadvantages can be avoided by using the steam turbocharger system. Fig. 2 shows a schematic view of a steam turbocharged combustion engine. The steam turbocharger system uses only the thermal energy of the exhaust gases for producing superheated steam in a steam generator. This steam expands in a small turbine to produce the required power for the compressor. Having passed through the turbine the steam enters the condenser. The condensate is then pumped back to the steam generator, thus completing the Clausius-Rankine-cycle. The main advantage of the steam turbocharger system 

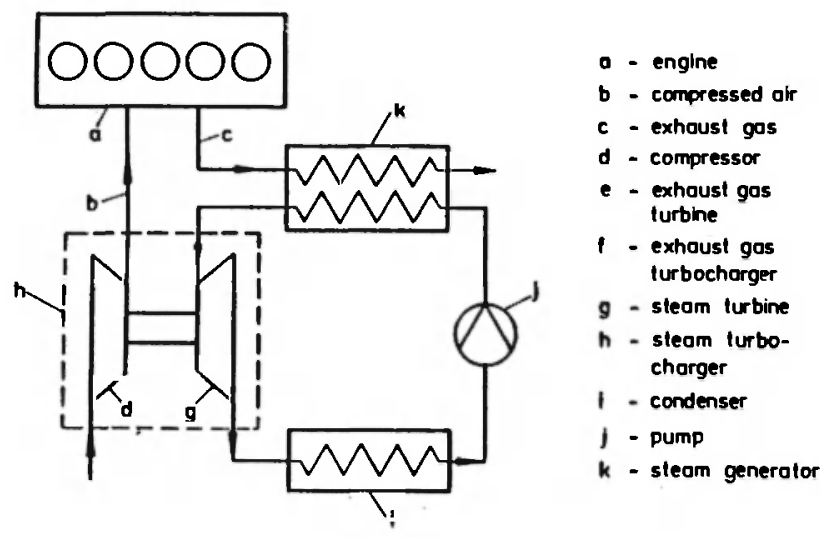

Fig. 2: Steam turbocharger system.

is that the engine operates with a positive pumping loop over the whole engine operating range. This is because the steam generator represents a very low resistance to the flow in the exhaust gas flow path so that the exhaust gas back pressure is almost atmospheric (see case B, Fig. 3). The conventional turbocharger operates with a positive pumping loop (see case Al in Fig. 3) only in a small part of the engine

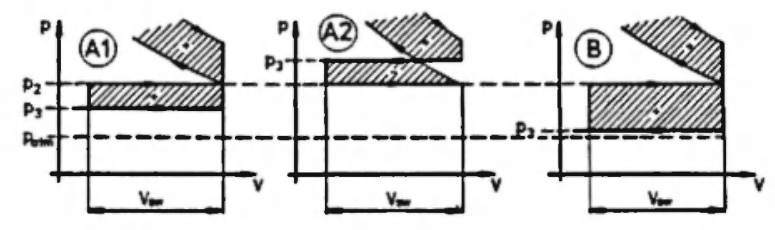

Fig. 3: Different pumping loops in $p, v$ diagram for A1) an engine supercharged by a conventional turbocharger (positive pumping loop), A2) an engine supercharged by a conventional turbocharger (negative pumping (oop), B) an engine supercharged by a steam turbocharger.

operating range. But in the larger part of the engine operating range the value of back pressure $p_{3}$ is greater than the boost pressure $p_{2}$, which means that the engine works similar to a natural rated engine (see case A2, Fig. 3). This can also be seen from Fig. 4, which shows the operating range of a 3.01 turbocharged diesel engine. The thin lines represent the operating points with a constant pumping loop pressure ratio $\pi_{2.3}=p_{2} / p_{3}$. A positive loop means $\pi_{2,3}>1$, a negative pumping loop means $\pi_{2,3}<1$.

Small steam turbines in the power range of about $10 \mathrm{~kW}$ used in a steam turbocharger system require a

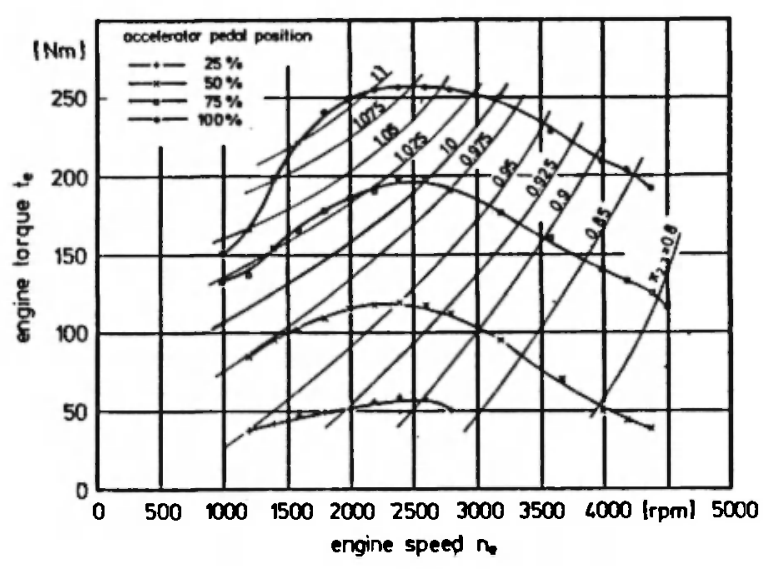

Fig. 4: Pumping loop pressure ratio $\eta_{2,3}=p_{2} / p_{3}$ shown in the engine load map.

special design $/ 1,2 /$. The limited waste heat supply of the combustion engine implies very small steam mass flow rates of about 0.03 to $0.08 \mathrm{~kg} / \mathrm{s}$. To attain high cycle efficiency of the Clausius-Rankine-cycle, the enthalphy drop of the turbine should be as high as possible. These conditions lead to supersonic flow and partial admission of the turbine rotor $/ 3 /$. A comparison (based on theoretical considerations) of different turbine types suitable for the proposed steam turbocharger system has already been made 14/. The results of these investigations prove the Pelton principle to the most practical, mainly because of its high enthalpy drop and the simplicity of its construction. Calculations for the thermodynamic cycle optimization of the complete Clausius-Rankinecycle matched with a combustion engine have already been carried out too, in order to obtain the main parameters for the turbine design $/ 5 /$.

\section{The Steam Turbine}

In the construction of the steam turbocharger the radial compressor and the bearing housing could be taken from a Kühnle, Kopp \& Kausch conventional exhaust turbocharger type K26. The shape of the Pelton turbine was such that a problem-free adaption to the given bearing housing was possible. The starting point for the design of the steam turbocharger is the performance requirement and the speed range of the radial compressor. The Pelton turbine is an impulse turbine which is also suitable for extreme partial admission. It is capable of reducing a very high drop in enthalpy in one stage only. The partial admission of the turbine wheel is made by nozzles 
arranged on the periphery which accelerate the superheated steam up to Mach numbers $M_{t}>1$ before it enters the rotor. The nozzles which replace the stator transform the complete enthalpy drop into velocity so that no expansion takes place in the rotor with its bucket-shaped vanes, but rather an attempt is made to reach the furthest possible deflection of the jet to produce circumferential force. The power of the Pelton turbine can be calculated by tangential incident flow as

$$
P_{t}=m_{s t} \cdot U_{3,1}\left(C_{3,1}-U_{3,1}\right) \cdot\left(1+\cos \beta_{4,2}\right)
$$

The maximum efficiency of the Pelton turbine $\eta_{\mathrm{t}}$ has been theoretically reached if the buckets are moving with a velocity equal to about $50 \%$ of that of the impinging jet

$$
c_{3,1}=2 u_{3,1}
$$

For this case the turbine efficiency can be calculated as

$$
\mathrm{P}_{\mathrm{t}}\left(\eta_{\mathrm{t}, \mathrm{max}}\right)=\frac{\dot{\mathrm{m}}_{\mathrm{st}} \cdot \mathrm{c}_{\overrightarrow{\mathrm{J}} \mathrm{i}}^{2}}{4}\left(1+\cos \beta_{4.2}\right)
$$

To drive the compressor at a speed of approx. $100000 \mathrm{rpm}$ a load of $8 \cdot 10 \mathrm{~kW}$ is needed, depending on the mass flow of the compressor. With the following assumptions

$$
\begin{aligned}
\dot{m}_{\mathrm{t}} & =0.03 \mathrm{~kg} / \mathrm{s} \\
\mathrm{u}_{3,1} & =400 \mathrm{~m} / \mathrm{s} \\
\mathrm{c}_{3,1} & =850 \mathrm{~m} / \mathrm{s} \\
\mathrm{w}_{3,1} & =450 \mathrm{~m} / \mathrm{s} \\
\beta_{4,2} & =15^{\circ}
\end{aligned}
$$

the turbine efficiency can be calculated as $P_{t}=10.6$ $\mathrm{kW}$. In order to obtain a jet velocity of $c_{3,1}=850$ $\mathrm{m} / \mathrm{s}$, a drop in enthalpy of $\Delta \mathrm{h}_{\mathrm{t}}=360 \mathrm{~kJ} / \mathrm{kg}$ is required. Assuming that the efficiency of the nozzles is $\eta_{\mathbf{n}}=.95$, then the isentropic enthalpy difference is $\Delta \mathrm{h}_{\mathrm{t} . \mathrm{s}}=\Delta \mathrm{h}_{\mathrm{t}} / \eta_{\mathrm{t}}=379 \mathrm{~kJ} / \mathrm{kg}$. Since the steam should not be expanded into the wet steam area there is a state of steam for the turbine inlet of $p_{t o t, 3}=6 \mathrm{bar}$ and $T_{\text {tot } 3}=300^{\circ} \mathrm{C}$, when the state of steam at the turbine exit for the isentropic case on the saturation line is taken as $\mathrm{p}_{\text {tot, } 4}=1$ bar and $\mathrm{T}_{\text {tot. } 4}=100^{\circ} \mathrm{C}$, and the steam velocity in front of the nozzle is assumed to be approximately at nought.

Figure 5 shows a cross-section of the whole steam

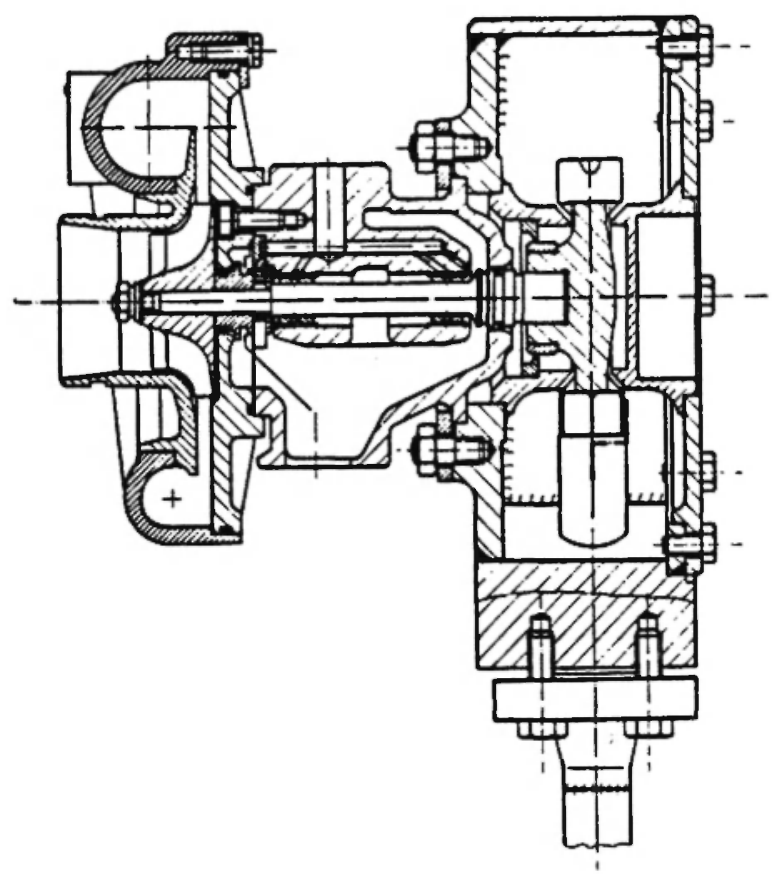

Fig. 5: Cross-sectional view of the complete steam turbocharger.

turbocharger. Whilst the welded construction of the turbine housing was made from corrosion-resistant V2A steel, a special aluminium alloy of great durability was used for the two turbine wheels tested up to now because it has a smaller moment of inertia and is easier to work with. As shown in Fig. 6 the turbine

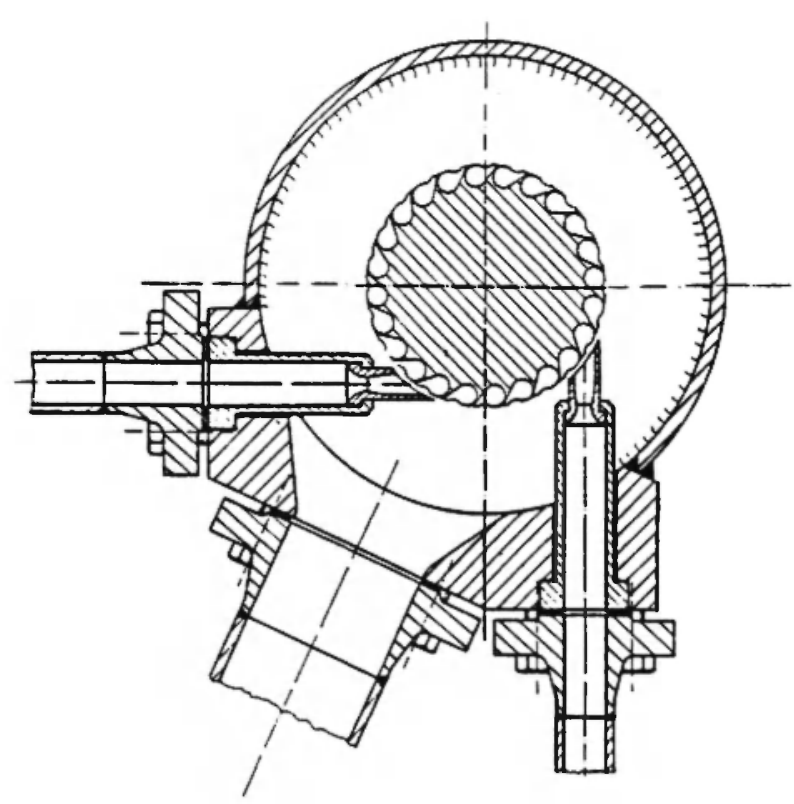

Fig. 6: Cross-sectional view of the Pelton steam turbine with rotor 2. 
rotor is driven by two supersonic nozzles each set at $90^{\circ}$. A computer program was written to design the supersonic nozzles with their sharp-edged throat $16,7 /$. This program uses the method of characteristics to define the contours of the diverging supersonic part of the nozzles. The method of characteristics as applied to the two-dimensional isentropic flow of an ideal gas was used for the design in a manner analogous to that described in references $/ 8 /$ and $/ 9 /$. Fig. 7 shows a cross-section of the supersonic nozzles used in the tests. The nozzles were installed and secured in the turbine in such a way that in further tests they can be easily changed.

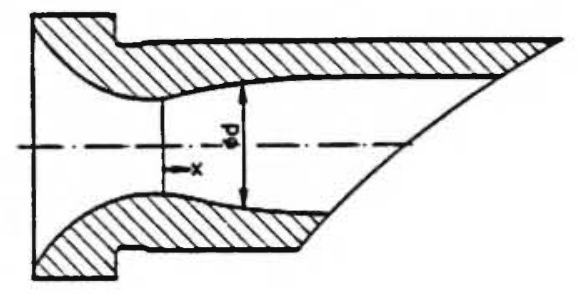

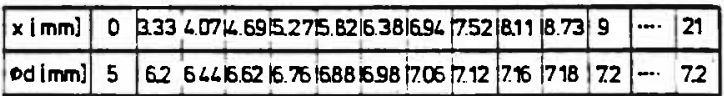

Fig. 7: Cross-sectional view of the supersonic nozzle.

The diameter of the rotor wheel was chosen so that, on the one hand, approx. $110000 \mathrm{rpm}$ could be achieved for a circumferential velocity of $400 \mathrm{~m} / \mathrm{s}$ and on the other, the demands of the centrifugal force made on the material used remained within the boundaries permitted. With a relative flow velocity of $w_{3,1}=450 \mathrm{~m} / \mathrm{s}$ and a nozzle exit speed of $c_{3.1}=850$ $\mathrm{m} / \mathrm{s}$ a turbine wheel diameter of $d_{3.1}=70 \mathrm{~mm}$ is obtained. As mentioned, two different turbine rotors have been examined within the framework of this report (see fig. 8). Both rotors were made from one piece. The material is a special aluminium alloy (AlCuMg IF 38) of great durability. The bucket-shaped vanes (buckets) were, in both cases, produced with the help of a milling machine. Rotor 1 possesses 16 individual bucket-shaped vanes. The inlet flow angle was taken to be 0 and the central splitter of the buckets is formed as sharp edges for zero indidence. The outer diameter of the wheel measures $d_{o}=84$ $\mathrm{mm}$, the middle wheel diameter $\mathrm{d}_{\mathrm{m}}=72 \mathrm{~mm}$. The second rotor is made of the same material and consists of 24 integrated buckets. This rotor has the
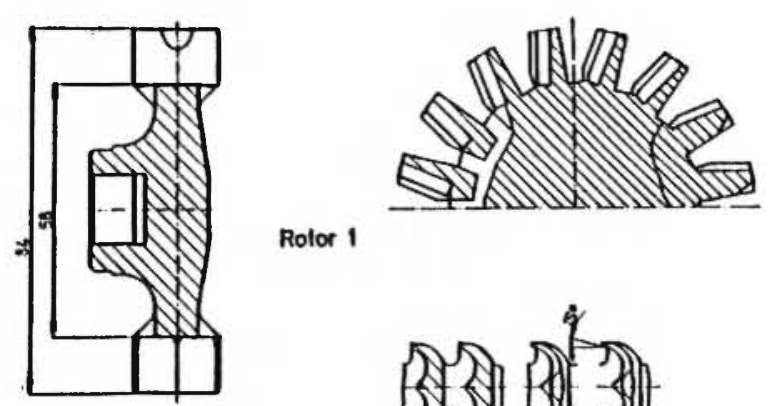

Rolor 1
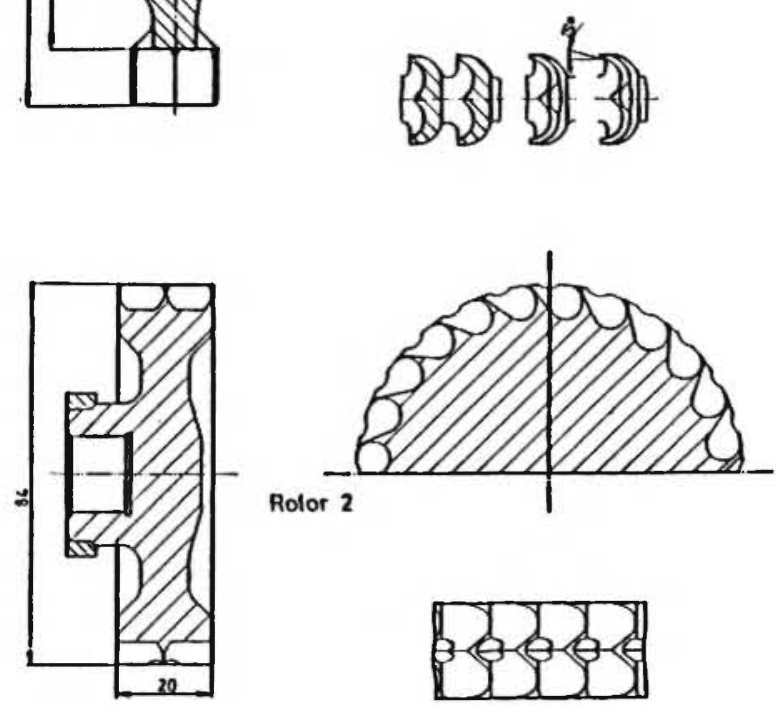

Fig. 8: Cross-sectional view of rotor 1 and rotor 2.

same outer diameter as the first rotor $(84 \mathrm{~mm})$. The buckets were designed in a different way to give the flow a turn angle in all directions thus making them able to absorb a larger part of the jet energy. A view of rotor 2 adapted to the steam turbine can be seen in Fig. 9.

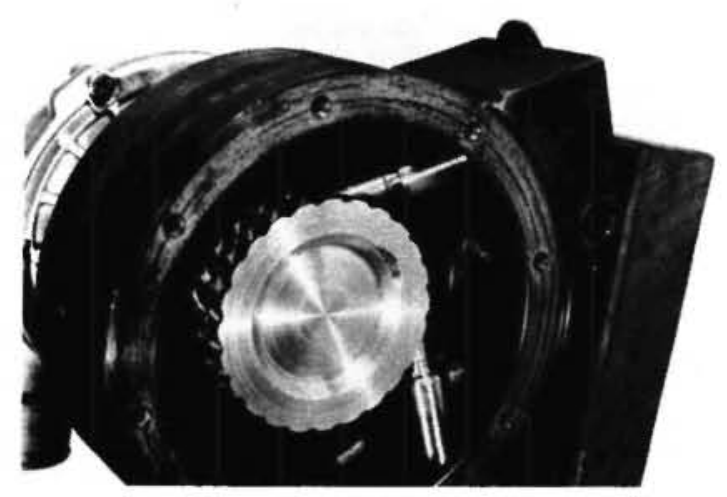

Fig. 9: View of the complete steam turbine with rotor 2. 


\section{The Test Rig}

As mentioned before, the steam turbine is the most critical part of the whole Clausius-Rankine-cycle. For this reason tests firstly had to be carried out with the steam turbine alone. Only after the completion of these tests can further tests on the whole ClausiusRankine-cycle with a combustion engine be performed. A special test rig has been built at the University's power plant where superheated steam is available from a pressure reduction station. The turbine inlet condition of the superheated steam can be varied here for large ranges of temperature, pressure and mass flow.

Fig. 10 gives a schematic view of the test rig. The turbine inlet pressure and the turbine mass flow are controlled by a throttle. The turbine back pressure value is used to realize a constant turbine pressure ratio at a higher turbine outlet pressure in order to obtain a higher enthalpy drop. On leaving the turbine the steam is carried through a water cooled condenser. The turbine mass flow is determined by weighing the condensate within certain time intervals. During the tests carried out the radial compressor was used as a brake to dissipate the generated turbine power. The compressor pressure ratio and the compressor mass flow rate can be regulated by a throttle valve. The value of compressor mas flow is determined with the help of a ventum tube in the compressor outlet delivery pipe. A separate oil supply system is used for the sliding bearings of the steam turbocharger. The pressures and temperatures are measured in the stations 1 and 2 for the compressor; 3 and 4 for the turbine shown in Fig. 10.

\section{Test Results}

No reference has been found on the usage of small high rotational steam turbines, used to drive a radial compressor within the form of a steam turbocharger arrangement, as is proposed in this paper. Neither was there any in-house experience with small partial admitted steam turbines rotating at high speed when the experiments were begun. So, the first series of tests served to establish whether the constructed steam turbine was, within the given marginal limits of a very small steam mass flow, indeed capable of driving the compressor within the whole of its operating range. The tests were, therefore, carried out in such a way that the map of the compressor, which was already known, was measured driven by the steam turbine. In other words, the operating points of the steam turbine were set up in accordance with the power demands required for the preceding compressor operating point. The turbine inlet temperature came to approx. $\mathrm{T}_{\text {tot }, 3}=573 \mathrm{~K}=300^{\circ} \mathrm{C}$ during the tests.

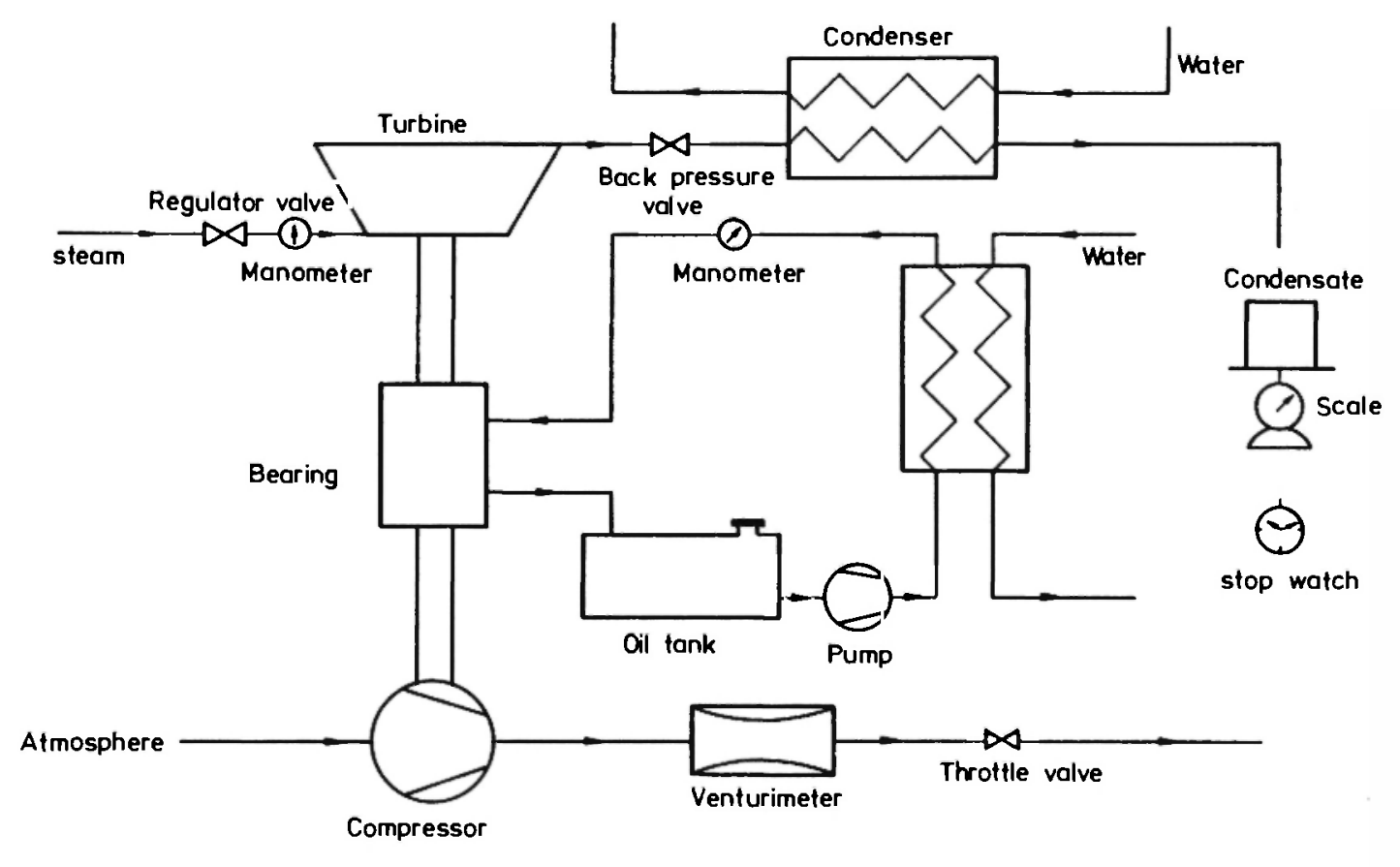

Fig. 10: Schematic view of the test rig. 
The turbine inlet pressure could be adjusted between 1 and 7 bars. Fig. 11 shows the familiar map of the compressor, the shaded areas showing where the steam turbine could operate to drive the turbocharger. It is clear that in the first series of tests the whole operating range could still not be covered. This could partly be put down to the fact that the permissible turbine inlet pressure had at first, for technical safety reasons, to be limited to a maximum of 7 bars, and partly because the turbine efficiency had still not reached the required values. Since the first two types of rotors were tested under the same conditions the recognizable difference in the possible operating field of the compressor (see Fig. 11) - as will be shown later in greater detail - can be attributed to the considerably differing turbine efficiencies.

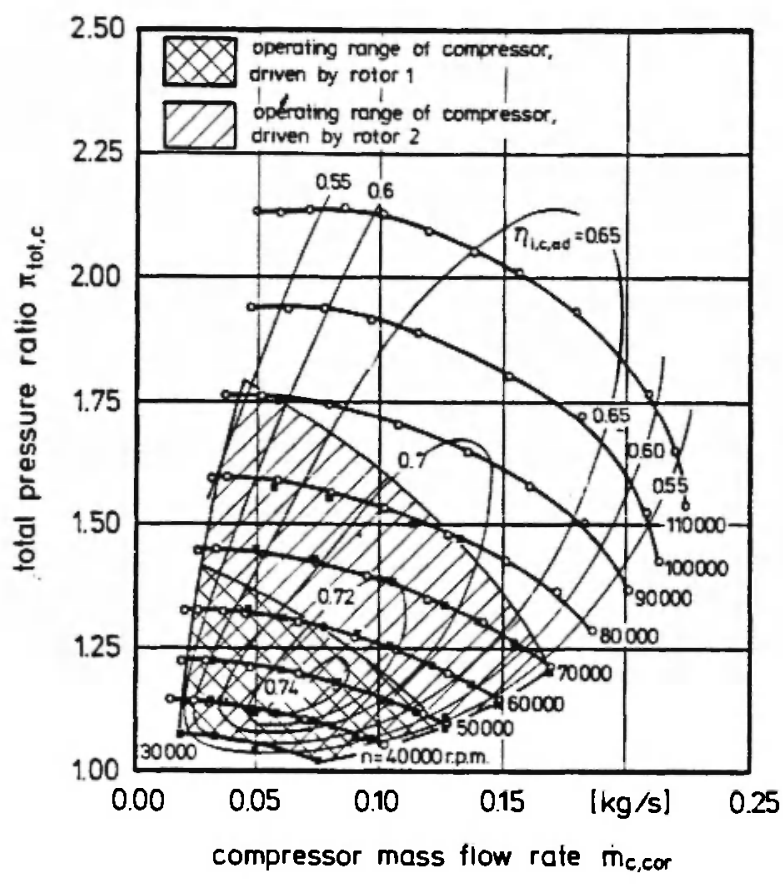

Fig. 11: Operating ranges of compressor driven by the Pelton turbine.

Fig. 12 shows the mass flow of the compressor, as a function of the turbine mass flow at different constant speeds. The operating points on the dotted line portray the operation of the compressor at the surge line. From this figure it is clear that for a constant speed, the air mass flow rate increases with the steam mass flow rate. If, for example, the compressor mass flow rate at a constant speed is doubled, then the steam mass flow rate through the turbine is on average increased by 1.3 times. The

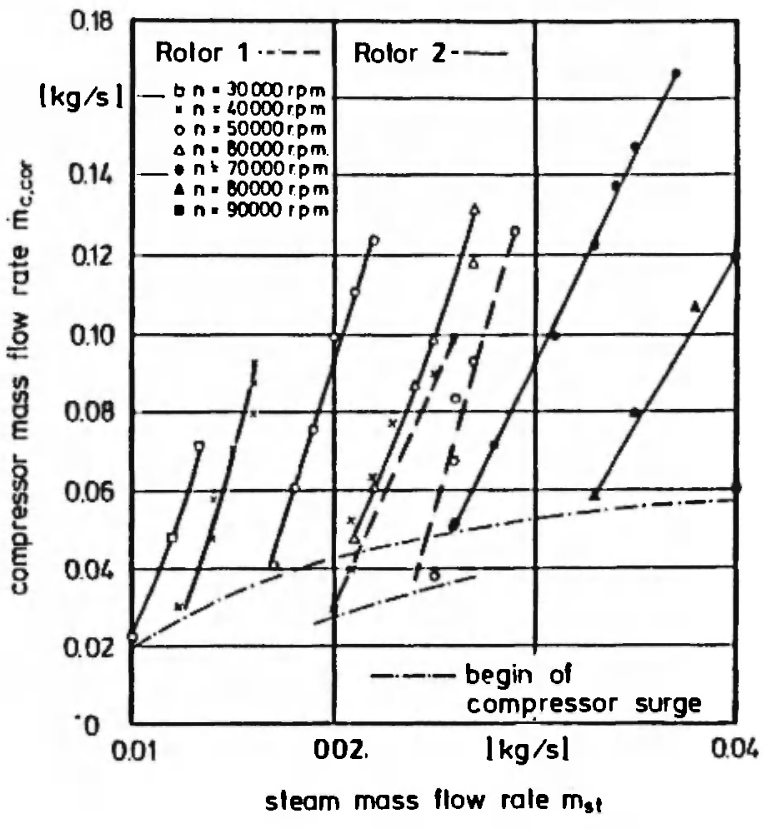

Fig. 12: Steam and air mass flow rates at different speeds.

comparison of the results of rotor 1 and rotor 2 shows that in the case of rotor 1 , at a speed of 40000 rpm and $50000 \mathrm{rpm}$ approx. 1.5 times the steam mass flow rate of rotor 2 is required with the same turbine inlet conditions. The turbine mass flow as a function of the turbine inlet pressure is shown in Fig. 13. At a

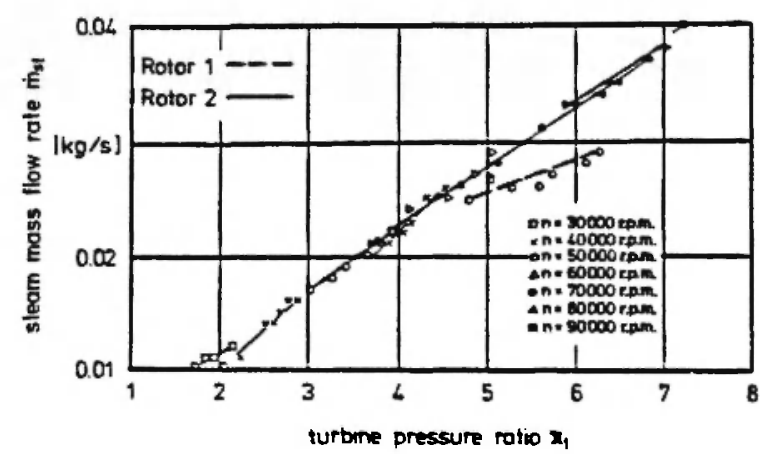

Fig. 13: Steam mass flow rate as a function of turbine inlet pressure at different speeds.

constant speed the steam mass flow rises with increasing inlet pressure. The mass flow characteristic of the turbine, as is shown clearly in this diagram, depends to a great extent on the turbine rotor used. In this case rotor 2 shows a more favourable mass flow characteristic. This becomes obvious when the 
speed lines of both rotors at $40000 \mathrm{rpm}$ and 50000 rpm are compared. These speeds can be obtained with rotor 2 at a considerably lower turbine inlet pressure and mass flow rate. The constant speed lines partly overlap. This is because the compressor in operation near the choke-line at a certain speed needs more power than it does when in operation near the surge line on the next higher speed line. This is just as obvious in Fig. 14 which shows the turbine power portrayed over the turbine mass flow rate. It is clear

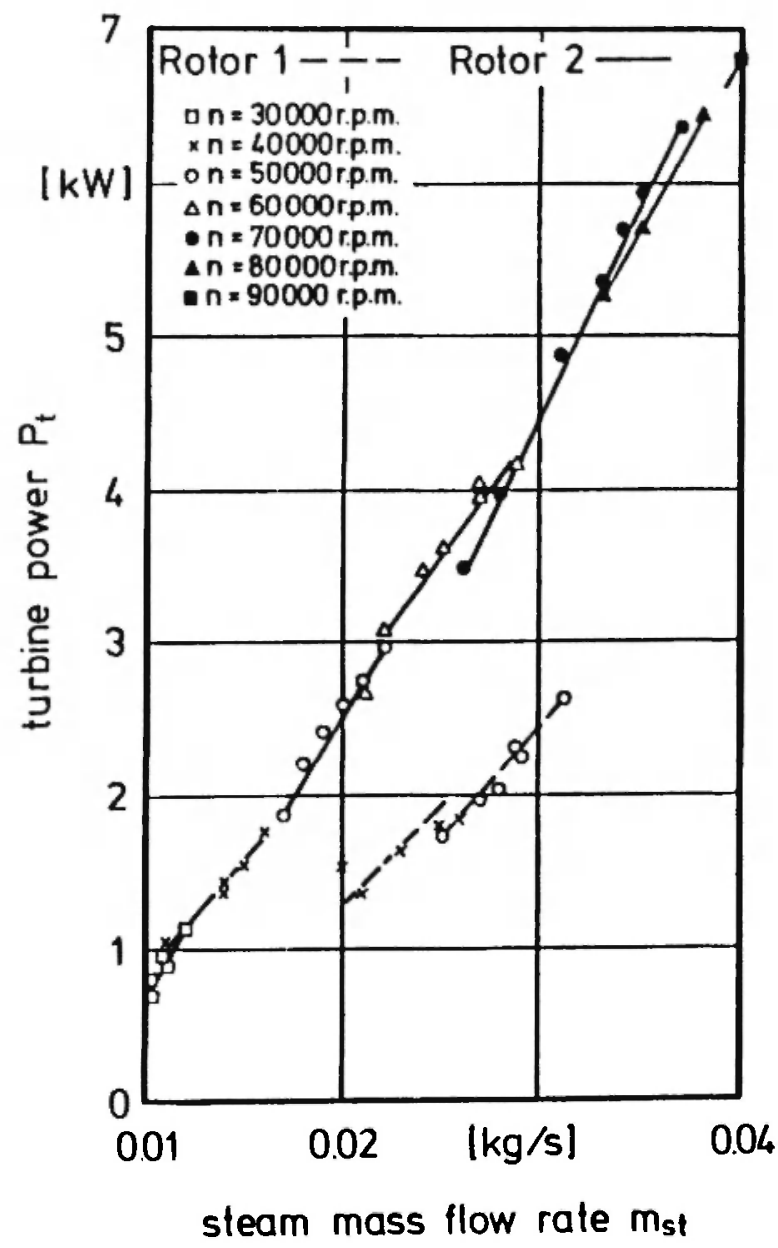

Fig. 14: Turbine power as a function of steam mass flow rates at different speeds.

that during the first tests a power range between .5 and $7 \mathrm{~kW}$ from the turbine was covered. Analogous to this is the compressor power which is shown in Fig. 15 as a function of the compressor mass flow.

Fig. 16 shows the effect of speed ratio $v=$ $\mathrm{u}_{3,1} / \mathrm{c}_{3,1, \mathrm{~s}}$ on the isentropic turbine efficiency $\eta_{\mathrm{t}}$. Whilst the efficiencies of rotor 1 lie in the region of

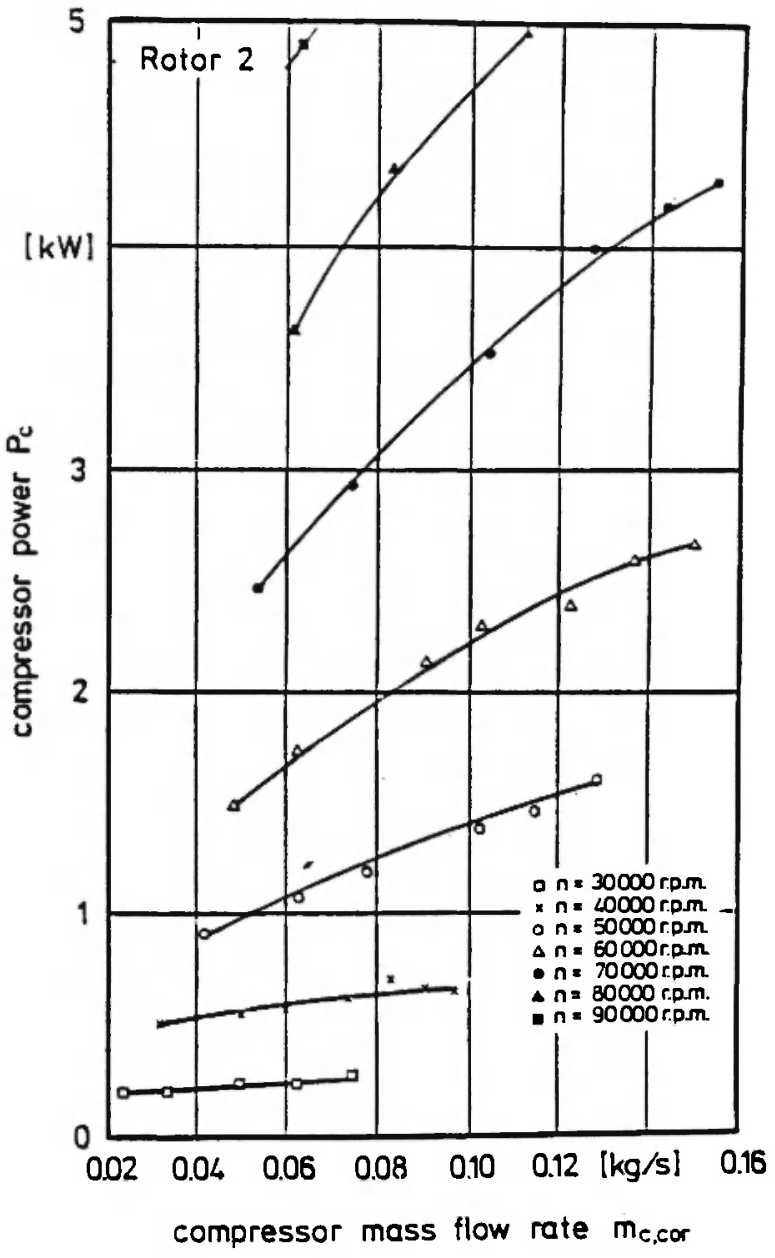

Fig. 15: Compressor power as a function of air mass flow rate for different speeds.

$20 \%$ to $3 \%$, with rotor 2 , efficiencies in the region of between $40 \%$ and $50 \%$ and more were measured. This range of efficiency values has been foretold for small steam turbines also in $/ 9 /$. From Fig. 16 it is evident that higher values of turbine efficiency can be obtained at lower speeds and vice versa. This trend is quite surprising since the efficiency was expected to increase with an increasing velocity ratio. Errors in temperature measurement can be ignored because the turbine inlet temperature was measured at two different places. This was also done for the turbine outlet temperature. Since the turbine outlet flow is free of swirl the temperature measurement at this point is not so imperfect as it is in the case of an exhaust gas turbocharger. And last but not least, the turbine was insulated so that effects of heat transfer can be ignored. The effect (that the turbine efficiency decreases with an increasing velocity ratio $\nu$ ) can be explained by the fact that an increase of turbine 


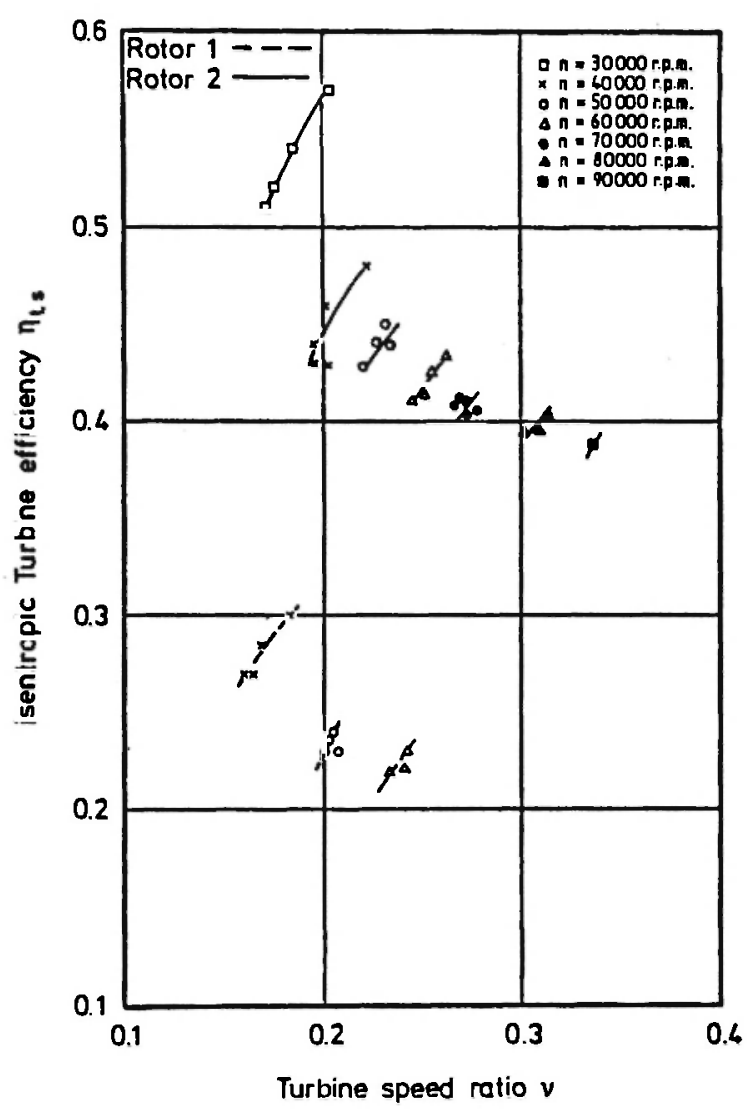

Fig. 16: Isentropic turbine efficiency as a function of turbine speed ratio $\nu=u_{3.1} / c_{3.1 \mathrm{~s}}$.

speed leads to an increase of partial admission losses and to an increase in rotor friction losses. It is known that the value of these losses is proportional to the third power of rotor speed. That means that a constant velocity ratio of $\nu=0.2$, for example, which is obtained at a low rotor speed and a low isentropic enthalpy drop leads to a better turbine efficiency as is the case when the same velocity ratio is obtained at a high rotor speed and high isentropic enthalpy drop.

The considerable difference of efficiency between rotor 1 and rotor 2 at constant speed can be attributed to the differences in the shape of the buckets of both rotors. This is true because in both cases the diameter of the turbine rotor, the turbine casing and the operating conditions were the same The advantage of rotor 2 is given by the hemispherical shaped buckets, since these lead to a greater deflection in both tangential and radial direction than is the case with rotor 1 with its radial ending buckets. Another advantage of rotor 2 is that the hemispherical shaped buckets allow the steam to leave the buckets unhampered. On the other hand with rotor 1 the possibility exists that a part of the steam leaving one bucket will hit the next one. This results in an impulse in the opposite direction of rotation.

\section{Conclusions}

A steam turbocharger has been proposed, which uses the waste heat of a combustion engine to supercharge the cylinders. This steam turbocharger system was compared with the conventional waste gate controlled turbocharger. A small Pelton turbine for steam was machined and matched to a radial compressor of a conventional turbocharger used in cars. The first tests were carried out without an engine, on a special test rig which is supplied with superheated steam from a power plant. The tests were performed keeping the turbine inlet temperature constant at $300^{\circ} \mathrm{C}$. The turbine inlet pressure was varied between 1 and 7 bars. Two different types of turbine rotors were tested from which the following results were obtained. The shape of the turbine rotor buckets has a large influence on the turbine perform. ance, especially on the turbine efficiency and turbine power. During the tests the steam mass flow rate was varied between 0.01 and $0.04 \mathrm{~kg} / \mathrm{s}$ and the generated turbine power range from 0.5 to $7 \mathrm{~kW}$ depending on the rotor type. The maximum turbine speed was $60000 \mathrm{rpm}$ for rotor 1 and $90000 \mathrm{rpm}$ for rotor 2 . The values of isentropic turbine efficiency for rotor 1 are between $22 \%$ and $30 \%$ and for rotor 2 between $38 \%$ and $56 \%$ depending on the turbine speed and the turbine inlet pressure. On the compressor side a pressure ratio of 1.3 with rotor 1 and 1.7 with rotor 2 was obtained. Noteworthy is the fact that higher values of turbine power and compressor pressure ratios can be obtained by raising the turbine inlet pressure and temperature or by decreasing the condenser pressure. The tests have, however, also shown that further investigations have to be done with the steam turbine, i.e. different shapes of rotors, nozzles and casings have to be designed and tested to obtain an optimum high speed steam turbine for the proposed steam turbocharger.

\section{Acknowledgements}

The authors wish to express their appreciation to Mr. H. Foss and Mr. H. Quietmeyer who prepared and skillfully operated the test rig, and to Mr. H. Diel for his help in preparing the paper layout. 


\section{References}

1. K. Korematsu and N. Hirayama, "Performance Estimation of Partial Admission Turbines", ASME Paper No. 79-GT-123, Dec., 1977.

2. A.T. Dusnatan, "The Design, Testing and Application of a Small High Speed Inward-Flow Radial Turbine", Thesis submitted for PhD, Oxford University, 1981.

3. K. Bammert, H. Heikal and A. Mobarak, "Turbomachinery for Small Solar Power Plant", Forschung im Ingenieur-Wesen, Vol. 47, No. 6, pp. 169-200, 1981.

4. M. Rautenberg, A. Mobarak, M. Abdel Kader and C. Meyer, "Comparison of Different Small Steam Turbines for Steam Turbocharger", ASME Paper No. 84-GT-239, Amsterdam, June, 1984.

5. M. Rautenberg, M. Malobabic, A. Mobarak and M. Abdel Kader, "A Small Pelton Turbine for Steam Turbocharger", Proceedings of the 19th Intersociety Energy Conversion Engineering Conference 84, San Francisco, August 19-24, 1984.
6. M.R. Vanco and L.J. Goldman, "Computer Program for Design of Two-dimensional Supersonic Nozzle with Sharp-edged Throat", NASA, TMX-1502, 1968.

7. M. Abdel Kader, "The Design and Testing of a Small Turbine for Steam Turbocharger used in Gasoline Vehicles", Thesis, Cairo University, Faculty of Engineering, Giza, Egypt, 1984.

8. A.H. Shapiro, "The Dynamics and Thermodynamics of Compressible Fluid Flow", Vol. 1, Ronald Press Co., 1953.

9. A.H. Shapiro and G.H. Edelmann, "Method of Characteristics for Two-Dimensional Supersonic Nozzle with Sharp-Edged Throat", NASA, TMX-1502, 1968.

10. F. Dietzel, "Dampfturbinen als Krafterzeuger in Industriebetrieben", Maschinenmarkt, 82(59), pp. 1057-1060, 1976. 